\title{
LOS SENDEROS DE LA IDOLATRÍA: EL VIAJE DE VÁZQUEZ DE ESPINOSA POR LOS ALTOS DE ARICA, 1618
}

\author{
PATHWAYS OF IDOLATRY: THE JOURNEY OF VÁZQUEZ DE ESPINOSA \\ AROUND THE ALTOS DE ARICA, 1618
}

\author{
María N. Marsilli ${ }^{1,2}$ y Priscilla Cisternas ${ }^{3}$
}

\begin{abstract}
El artículo examina el "Compendio y Descripción de las Indias Occidentales" elaborado por el carmelita Antonio Vázquez de Espinosa en los segmentos del texto dedicados a su visita a los Altos de Arica. Aun cuando el cronista es un viajero acucioso, su texto no ha estado exento de cuestionamientos y críticas. A la vez, el espíritu de la obra del carmelita se inscribe en una corriente de literatura científica del Nuevo Mundo que posee tonos éticos inherentes a la labor apostólica de la conquista espiritual de los indios. No obstante tales consideraciones, las observaciones registradas para la zona ofrecen una valiosa información sobre el panorama religioso de las comunidades andinas del Corregimiento de Arica. El abandonado estado de las iglesias, la carencia de prelados y el deplorable estado de la evangelización de los indígenas dan cuenta cómo, a pesar de los esfuerzos desplegados por la Iglesia, los indígenas continúan rearticulando sus creencias religiosas tradicionales.
\end{abstract}

Palabras claves: idolatría, evangelización, Altos de Arica, Antonio Vázquez de Espinosa.

This article examines a colonial description of the area known as the Altos de Arica, produced by the Carmelite friar Antonio Vázquez de Espinosa in his "Compendio y Descripción de las Indias Occidentales". The text essentially constitutes a sample of $17^{\text {th }}$ century scientific literature about the New World which possesses ethical undertones of the spiritual conquest of the Indians. Although detailed, the chronicler's descriptions have been questioned. In spite of its possible limitations, Vázquez de Espinosa's observations convey valuable information regarding the state of Indian conversion in Andean communities of the Corregimiento of Arica. The abandonded state of parochial churches, the absence of prelates or high ranking church officials, and the deplorable state of Indian conversion show that, in spite of the efforts by the colonial church, indigenous populations still managed to hold on to their traditional religious practices.

Key words: Idolatry, evangelization, Altos de Arica, Antonio Vázquez de Espinosa.

En 1618, el carmelita descalzo Antonio Vázquez de Espinosa escribió para los Altos de Arica: "Quemé un pueblo que se llamaba Isquiliza, porque los mas eran idólatras, muchos avían que no se avían confesado en su vida" (Vázquez de Espinosa, 1948 [1636]: párrafo 1416, p. 481). La cita ha sido usada profusamente en estudios regionales de historia colonial. Probablemente porque la violenta decisión por parte del fraile constituye una denuncia que indica que -a la fecha- la evangelización de los Andes del Sur no se desarrollaba adecuadamente, anticipando así en algunos decenios las célebres campañas de extirpación de idolatrías que se sucedieron en la zona de los Andes centrales a mediados del siglo XVII. Cabe, no obstante, preguntarse: ¿es fiable la fuente producida por el carmelita? ¿Son sus observaciones representativas de la situación por la que atravesaba la conversión nativa en la zona hacia inicios del siglo XVII?
Las observaciones del carmelita, sin duda, invitan a reconsiderar el proceso de adoctrinamiento religioso en el Corregimiento de Arica. Vázquez de Espinosa denuncia, como "testigo de vista", factores fundamentales como la ausencia de curas, el abandonado estado de las iglesias y la falta en la entrega de los sacramentos a los indígenas, todos elementos de análisis que permiten suponer que la labor realizada por los agentes del catolicismo español no era exitosa.

A pesar de las drásticas políticas implementadas por la administración eclesiástica hispana para hacer más eficaz la evangelización de las comunidades indígenas (como la subdivisión de territorios eclesiásticos ya existentes y la creación de nuevos obispados) el relato entregado por Vázquez de Espinosa denuncia la persistencia de prácticas idolátricas entre los indios, además de acusar la

\footnotetext{
History Department, John Carroll University, Cleveland, USA. mmarsilli@ jcu.edu

2 Centro de Investigaciones del Hombre en el Desierto, Universidad de Tarapacá, Arica, Chile.

3 Programa Magíster en Historia, mención Etnohistoria Universidad de Chile, Santiago, Chile. pricecisa@ hotmail.com
} 
carencia de control eclesiástico en las zonas más alejadas de los grandes centros ${ }^{1}$.

El "Compendio y Descripción de las Indias Occidentales" es una de las pocas fuentes para la historiografía local que contiene antecedentes sobre la religiosidad andina. El propósito del presente trabajo es examinar el panorama religioso de los Altos de Arica en los albores del siglo XVII a la luz de las descripciones, acusaciones y sospechas elaboradas por Fray Vázquez de Espinosa² ${ }^{2}$

\section{El Autor y su Obra}

El "Compendio" permaneció por más de tres siglos en el anonimato, hasta que en 1929 Charles Upson Clark encontró el manuscrito en la Biblioteca Barberiana en Roma. El texto debió ser adquirido por el Cardenal Barberini, quien visitó España entre los años 1725-1726 y cuya biblioteca fue incorporada al Vaticano donde se conserva hasta la actualidad ${ }^{3}$.

La vida de Vázquez de Espinosa se ha mantenido en el mismo misterio que su obra. Las primeras referencias indican que nació en Jerez de la Frontera en el último tercio del siglo XVI ${ }^{4}$. Se ordenó carmelita descalzo, residiendo en Jerez hasta que, en 1612, se lo encuentra radicado en México. El autor escribió varios textos durante su vida, algunos de ellos fueron redactados durante su viaje por América ${ }^{5}$. Retorna a España en 1622, residiendo algún tiempo en Málaga, Madrid, Sevilla y otros puntos. Durante los últimos años de su vida el carmelita presentó a la corte de Felipe IV al menos once memoriales que incluyen recomendaciones sobre la defensa armada de las Indias y resoluciones sobre el valor ético y material de la plata ${ }^{6}$. Sabemos que al momento de su muerte, en 1630, se hallaba compilando el enciclopédico "Compendio y Descripción". Asimismo había solicitado permiso apostólico para regresar al Nuevo Mundo a fin de fundar un convento carmelita, objetivo que nunca logró (Lehman 2008:82).

Con toda probabilidad su viaje a América lo ayudó a obtener un cargo de importancia a su regreso a España. Existen antecedentes que indican que se desempeñó como consultor del Santo Oficio de la Condesa de Olivares. Esta posición era con seguridad un cargo importante, ya que su esposo, el Conde Duque de Olivares, era un hombre destacado en la corte española y realizaba por esos años importantes cambios para el gobierno del rey Felipe IV ${ }^{7}$.
Sabemos del significativo rol que cumplieron los confesores en la corte española, quienes en muchas ocasiones actuaban como consejeros privados ${ }^{8}$. Lo más probable es que Vázquez de Espinosa se haya convertido en el geógrafo informante del CondeDuque en los asuntos tocantes a las Indias por el sabido interés que el Rey tenía en la geografía de sus dominios 9 .

Estamos, entonces, de frente a un fraile letrado, con extensa experiencia mundana lograda en sus viajes, quien está habituado a buscar y mantener estrechas alianzas con las más altas esferas del poder político en la corte del imperio español. Muy probablemente, debido a la posición política que Vázquez de Espinosa-después de todo un hombre de fe- logró ocupar en su vida es que el autor mezcla en sus escritos temas sociales, económicos y políticos con paradigmas morales del campo espiritual. Esta tendencia corresponde a una corriente de popularidad creciente en la literatura colonial hispanoamericana conocida como "hibridización", esto es, digresiones narrativas que albergan una simultaneidad de discursos a su vez vinculados con agendas normalmente polifacéticas de los autores (para el caso que nos ocupa, la agenda política, religiosa y de poder personal que con seguridad cultivaba Vázquez de Espinosa) (Lehman 2008:83).

Observaciones científicas, en particular las vinculadas a la geografía física y humana de las Indias, constituyen un elemento primordial en las observaciones registradas por el carmelita durante su viaje. Dada la naturaleza de la posición política ocupada por el autor a su regreso a España, cuando comienza a escribir sus obras, descripciones de esta índole seguramente también estaban destinadas a asegurar al carmelita un lugar en la comunidad científica de Europa, tema que merece un estudio detallado $^{10}$.

Vázquez de Espinosa comenzó a escribir el "Compendio" al retorno de su viaje por América, probablemente entre los años 1628 y $1629^{11}$. A pesar del interés que suscitaba su posible publicación, la muerte de su autor hizo que circulara sólo una parte impresa, quedando 194 páginas sin publicarse. $\mathrm{La}$ importancia que la obra tendrá a futuro para los estudios coloniales fue anticipada por el amigo de Vázquez de Espinosa, León Pinelo, quien declaró: "La descripción de las Indias es obra grande i de muchas noticias i la mas copiosa que en la materia aia salido" (Upson Clark 1948: III). Poca duda cabe que León Pinelo estaba en lo correcto. 


\section{Descripción de los Altos de Arica}

Vázquez de Espinosa ingresa a Arica por el fértil Valle de Chacalluta "donde se da el trigo y el maíz en abundancia". Atento a la geografía física, destaca que en el medio del valle se encuentra el pueblo de indios de Lluta, en donde el agua "por ser de azufre y alumbre" no permite los cultivos de viñas ni olivares, y en donde se ubica el camino Real de Arica a Potosí (Vázquez de Espinosa, 1948 [1636]: párrafo 1414, p. 479).

En una de las primeras referencias a la ciudad de San Marcos de Arica, Vázquez de Espinosa dice haber sido testigo presencial de un temblor que habría ocurrido en 1618, en donde el mar se retiró y habría salido fuera de sus límites llevándose "toda una acera de casas" (Vázquez de Espinosa, 1948 [1636]: párrafo 1396, p. 470). Además, añade que la ciudad fue fundada por el General Ordoño de Aguirre el año 1600 , en un lugar "ruin y enfermo". Encuentra en la ciudad a 100 vecinos españoles, además de negros y yanaconas para el servicio de la ciudad y de las haciendas. Da cuenta de la existencia de una Iglesia Mayor y el Convento de Nuestra Señora de la Merced, y la Hermita de Santa Lucía. Comenta la importancia del puerto de Arica, donde llegan navíos de España, el azogue de Huancavelica y los embarques de plata de Potosí. Destaca que existe un Corregidor proveído por el Consejo y Oficiales Reales (Vázquez de Espinosa, 1948 [1636]: párrafo 1415-1416, pp. 479-480) ${ }^{12}$.

Fiel a su agenda catequizante sentencia que es urgente que el Corregimiento de Arica cuente con Obispo propio por las innumerables necesidades que padecen quienes lo habitan, como es el caso de Pica y Tarapacá donde "no han visto prelado desde que se descubrió la tierra". En una nota alarmante para el estado de la evangelización de los nativos, añade que "los indios por no ir tan lejos (a Arica, el centro urbano más cercano) no se casan, insistiendo así que la persistencia de la idolatría viene favorecida por falta de prelado y descuido de los sacerdotes". El autor se autoconstituye en testigo de vista de esto al recorrer en el año 1618 los pueblos de Lluta, Socoroma, Putre, Tocrama, Lagnama, Lupica, Sacsama, Timar, Codpa, Cibitaya, Isquiña, Pachica, San Francisco de Vmagata, Santiago de Vmagata, Chapiquiña, Asapa, ubicados a distancia considerable unos de otros ${ }^{13}$. El cronista indica que, dado que la mayor cantidad de los habitantes de la jurisdicción de Arica se encuentran viviendo en sus Altos, se hacen tanto más graves los efectos de la falta de sacerdotes en ese lugar. Es aún más enérgico al señalar que los curas y sacerdotes que estaban a cargo de los Altos de Arica no cuidaban de los indios, y que éstos sólo tenían el nombre de cristianos. Las iglesias se hallaban en tal estado de abandono que el carmelita dice les debió colocar puertas de palo "bautizando a muchas personas de edad bastante avanzada, mujeres paridas y muchacho de mucha edad" (Vázquez de Espinosa 1948 [1636]: párrafo 1416, p. 481).

La quema del pueblo de Isquiliza es, sin duda, el hecho que más destaca en su descripción. El acto fue llevado a cabo porque según el autor sus "habitantes eran idólatras, muchos de ellos nunca, en su vida, se habían confesado, y de a diez, doce y de a veinte años". Con este evento Vázquez de Espinosa culmina su exhorto sobre el adoctrinamiento de los habitantes del Corregimiento, anotando como corolario moralizante que si existiera prelado en Arica, "los indios tendrían más temor y cuidado de lo que hacían" (Vázquez de Espinosa 1948 [1636]: párrafo 1416, p. 481).

El carmelita termina la descripción del Corregimiento con referencias al Valle de Azapa, al que considera un paraíso de fertilidad, donde hay buenas viñas, olivares, molinos para hacer aceite y más de 8.000 botijas de vino (Vázquez de Espinosa 1948 [1636]: párrafo 1416, P. 481). Estos antecedentes son, sin duda, valiosos para estudios del período medio colonial en el área y han sido extensamente citados. No obstante, existen cuestionamientos a su validez que se detallan a continuación.

\section{Cuestionamiento de la Obra}

Un elemento que según algunos estudiosos resta veracidad a la obra son las distintas y extensas regiones que Vázquez de Espinosa sostiene haber visitado. Existen serias dudas de que recorrió las Antillas, Venezuela, Colombia y Bolivia (Villalobos 1968:22). En el caso del reino de Chile, la evidencia sugiere que algunos pasajes de su descripción habrían sido extraídos de otras fuentes, como las crónicas de Antonio de Herrera y del Inca Garcilaso de la Vega (Villalobos 1986:27).

Para el caso del Perú, el mismo Vázquez de Espinosa menciona que utilizó la descripción realizada en 1610 por Don Jerónimo Maldonado de Buendía, quien obedecía las órdenes del virrey Márquez de Montesclaros (Vázquez de Espinosa 


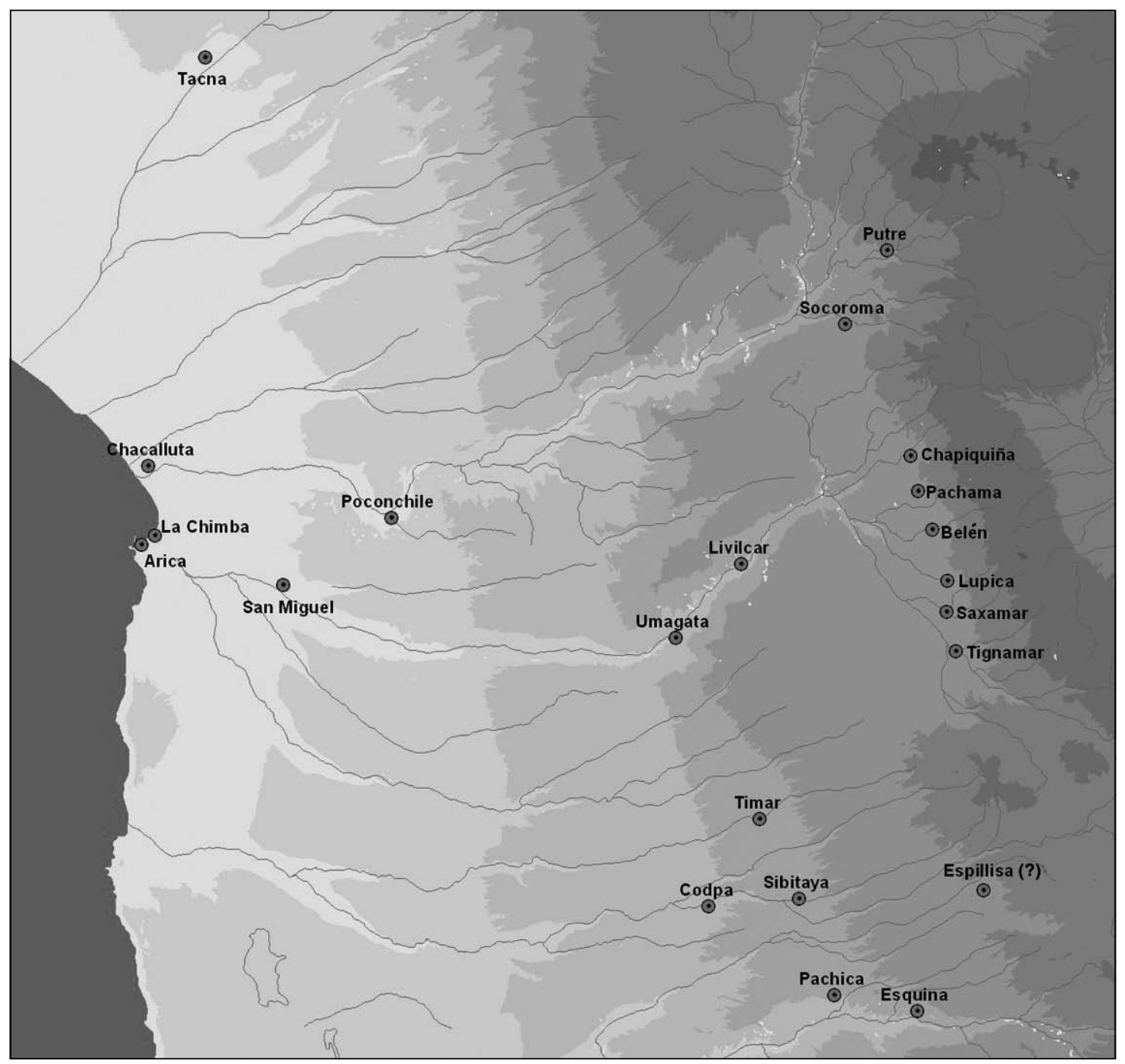

Figura 1. "Poblados visitados por Antonio Vázquez de Espinosa". Mapa elaborado por el arqueólogo Rolando Ajata. "Villages visited by Antonio Vázquez de Espinosa”. Map by archaeologist Rolando Ajata.

1948 [1636]: párrafo 1697 y 1709, pp. 606, 606 y 607$)^{14}$.

Otro cuestionamiento a la validez del "Compendio" es la fecha de los datos del censo de tributarios que aparecen en el texto. En el caso del Alto Perú, las cifras que el carmelita ofrece carecen de precisión, desconociéndose si fueron recogidas durante el mandato de Montesclaros, Luis Velasco o Esquilache (Sánchez-Albornoz 1978:22). Los antecedentes entregados carecen de valor cronológico y, debido a las limitaciones que permiten comprobar su veracidad, no queda claro si estos fueron copiados de fuentes oficiales en España o documentos a los cuales el carmelita tuvo acceso durante su viaje por América (Cook 1982:118). Estas imprecisiones han ocasionado que especialistas que han estudiado el "Compendio" se interroguen sobre quién copió a quién (Hidalgo 1980:678).

Pese a la controversia sobre la autoría y veracidad de los datos y el modo de recopilarlos, existen voces que destacan la autenticidad de la información compilada por muestro autor. La obra del carmelita aporta significativa información para estudios coloniales. Por ejemplo, las acabadas descripciones de valles, ciudades y jurisdicciones políticas del Virreinato del Perú constituyen testimonio valioso para los estudios étnicos en los Andes mediocoloniales (Pease 1995:49). Resulta por lo 
demás difícil (en virtud de la cantidad de antecedentes disponibles para el caso de Arica durante el siglo XVII) discernir cabalmente su veracidad. No obstante lo anterior, los datos contenidos en el "Compendio", especialmente en lo referido al estado de la evangelización en los Altos de Arica, coinciden -como veremos- en gran parte con los escasos documentos y crónicas de la época.

\section{Análisis de la Descripción de los Altos de Arica}

Una de las primeras denuncias que al autor hace es el notable ausentismo eclesiástico en la zona. La presencia de agentes del catolicismo colonial en el Corregimiento de Arica data de fechas tempranas. Los primeros sacerdotes llegados en compañía de Diego de Almagro en 1536 pertenecían a la Orden de Nuestra Señora de la Merced (Cúneo-Vidal 1977:71). Hacia 1565, el encomendero más importante de la zona, Lucas Martínez Vegazo, destinaba 568 pesos para la evangelización de los indios de Arica como lo disponía el Patronazgo Real, cuyas disposiciones hacían responsable al encomendero por la instrucción espiritual de sus indios (Trelles 1982:232). Los datos del censo recopilados para el Márquez de Montesclaros en 1614 identifican en todo el Corregimiento la presencia de seis clérigos y dos frailes (Cavagnaro 1994:113). A dicha fecha los curatos del Corregimiento eran los siguientes: Arica, Tarapacá (incluyendo Pica, Lanzama, Guabiña la Alta y Guabiña la Baja), Camiña (que incluía Sibaya, Usmagama, Chiapa, Sotoca, Estagama), Lluta y sus anexos, Tacna, Tarata y Putina, Sama e Ilabaya y Locumba (Cúneo-Vidal 1977:103). Estos seguramente corresponden a los curatos que a inicios del siglo XVII, según Vazquez de Espinosa, sufrían una notable falta de asistencia espiritual debido a la ausencia de sacerdotes.

El ausentismo de los religiosos de sus doctrinas constituyó una constante denuncia que los indígenas realizaron durante el período colonial. Los indios rápidamente se percataron de la importancia del requisito puesto por parte de la administración eclesiástica y denunciaron con vigor el ausentismo, usando el cargo como instrumento para negociar los límites efectivos de la autoridad del cura párroco. Por ejemplo, Francisco de Ávila, quien se erigió en el adalid de la correcta cristianización indígena, fue acusado en 1607 por los indios de San Damián de Huarochirí de abandonar constantemente su propia doctrina (Acosta 1987:556).
En el caso de los Altos de Arica, el ausentismo, o al menos las denuncias al respecto, constituyó con toda probabilidad una constante. Por ejemplo, en 1650, el Licenciado Bartolomé Cornejo Dávila, cura y vicario de Chacalluta, Codpa y Azapa, es acusado de no residir en su doctrina, ya que pasaba la mayor parte del tiempo en la ciudad de San Marcos de Arica exponiendo a sus feligreses a morir sin los sacramentos, falta que le costó severas penas (AAA, 1650, Arica-Codpa 1560-1891, Visita de la doctrina de Codpa y Azapa y sus anejos, 8 folios).

No residir en la doctrina constituía una falta grave que incluso podía ocasionar la pérdida de ésta. El Tercer Concilio Limense señala que el castigo que debían recibir los curas que se ausentasen de su doctrina era la pérdida de sus salarios, y que este dinero debía ser utilizado en la fabricación de iglesias o en atender las necesidades de su comunidad (Vargas 1951:349). La ausencia del "pastor" de la parroquia podía causar serias consecuencias en la evangelización de los indios y, por lo tanto, los castigos fueron severos. En el caso de la visita antes mencionada a Bartolomé Cornejo Dávila se determinó que - por sus reiteradas ausencias-al cura se le debía prohibir el viajar a Arica, bajo pena de quinientos pesos de multa. Además se le nominó un coadjutor para acompañarlo en todas sus visitas y muy posiblemente a fin de mantenerlo en el temor constante de una posible delación (AAA, 1650, Visita a la Doctrina de Codpa, fol.:7r.).

Cabe señalar que el aparato político y doctrinal del repartimiento se centraba en los Valles de Azapa y Lluta. Este hecho hacía el abandono administrativo tanto más serio (Hidalgo y Durston 2004:514). Es precisamente en ambos valles donde Vázquez de Espinosa denuncia el ausentismo eclesiástico como una constante. Esta denuncia no puede haber dejado indiferente a cualquier lector versado en la administración eclesiástica del imperio. La connotación es clara: es la irresponsabilidad de los curas párrocos lo que ha afectado adversamente la correcta evangelización de los indios.

Vázquez de Espinosa guía su narrativa entonces al corolario natural de la secuencia de argumentos presentados, esto es, el lamentable estado de la evangelización indígena. Los indios en la zona no tienen más que el nombre de cristianos, sentencia con severidad el viajero.

En descargo de los curas párrocos se debe señalar que las organizaciones políticas prehispánicas afectaron la distribución de los indígenas 
asignados a las doctrinas coloniales. Un ejemplo de esto lo constituyen los Carangas, quienes testificaron a comienzos del siglo XVII que varios pueblos serranos como de la zona, específicamente Socoroma, Tignamar y Pachica, debían ser adoctrinados por el cura de Turco, pese a estar bajo la administración del Corregimiento de Arica (Durston e Hidalgo 2004:493). A pesar de que limitaciones como éstas sin duda influyeron en la calidad de la conversión de los indígenas, las disposiciones de la iglesia especificadas en los Concilios categóricamente dictaminaban la importancia de otorgar con puntualidad los sacramentos a los nativos. Y el carmelita lo sabía.

Para Vázquez de Espinosa la responsabilidad del estado de la evangelización recae directamente en los clérigos, no en la naturaleza de los indios. El carmelita señala que los nativos son "gente de buena razón", quienes no incurrirían en prácticas idolátricas si hubiera prelados cuidándolos y adoctrinándolos (Vázquez de Espinosa 1948 [1636]: párrafo 1416, p. 481). Este discurso, en última instancia derivado de la noción del "buen salvaje", se conecta con los planteamientos que la Iglesia (o al menos un segmento de ella) propuso durante los primeros años de la evangelización. Esto es, cuando la iglesia colonial consideraba que el papel fundamental de los sacerdotes en la instrucción religiosa de los indios era el de ayudar a la conversión a través de la persuasión, dado que los nativos ya tenían un conocimiento natural de la verdadera fe. La responsabilidad por la fallida conversión no recaía en los nativos, sino en los sacerdotes (MacCormack 1986:19).

Es claro que la noción de conversión vía persuasión es un discurso limitado tanto en el texto como en la postura evangelizadora de Vázquez de Espinosa. Esto se manifiesta en una contradicción entre sus palabras y acciones. A pesar de conceder a los nativos la potencialidad de ser convertidos vía la persuasión, al proceder a quemar el pueblo de Isquiliza el autor en realidad se inclina a favor de un cambio de actitud que comienza a ser notorio en la evangelización en el Perú colonial desde fines del siglo XVI.

A partir de este momento entra en acción una segunda fase evangelizadora, en la cual se responsabiliza a los indios por no aceptar completamente el dogma cristiano. Dado que los indígenas no han abandonado sus antiguas prácticas se debe implementar una serie de castigos severos para quienes aún persistan en su idolatría. Sabemos que la tensión entre conversión por persuasión o violencia constituyó una pugna en la iglesia hispana y esta contradicción puede señalar el momento límite de la adopción irreversible de una postura decididamente más coercitiva por parte de la iglesia colonial en los Andes ${ }^{15}$.

Otro punto importante en la narrativa es su observación acerca del abandono en el que se encuentran las iglesias del área. En el Obispado de Arequipa tal situación evidencia una notable falta de preocupación de los curas de la zona por sus carreras eclesiásticas. Ha sido documentado en el sur andino que la construcción y decoración de las iglesias parroquiales constituía para los curas doctrineros una forma eficaz de lograr una promoción. Tal acción constituía una carta de presentación fundamental al momento de solicitar una mejor doctrina o puestos dentro del Cabildo Eclesiástico del Obispado (Marsilli 2002:68-71). Producto de estas acciones eran las estrechas relaciones que los sacerdotes debían mantener con las elites indígenas de sus parroquias, quienes organizaban la prestación de mano de obra nativa y coordinaban una buena paga por tales servicios. La estrecha relación que muchos parroquianos indígenas y sus curas lograron establecer en el Obispado de Arequipa constituyó un motivo importante para que los sacerdotes rehusaran perseguir causas de idolatría en contra de los indios (Marsilli 2004:409) ${ }^{16}$.

Es importante destacar que ya el Segundo Concilio Limense había puesto especial énfasis en la construcción de iglesias. El texto señala que "en los lugares pequeñuelos también se hagan sus yglesias donde se baptizen y se junten a la doctrina" (Vargas 1951:251). Para el Tercer Concilio Limense las iglesias continúan siendo importantes. El texto establece que en las visitas efectuadas a los curas doctrineros se considere la ornamentación y el estado de las iglesias como un elemento fundamental para evaluar las tareas efectuadas por los sacerdotes (Vargas 1951:363). Un iracundo Vázquez de Espinosa en su viaje por los Altos de Arica, entonces, ejecuta (o dice haber ejecutado) las disposiciones oficiales de la iglesia colonial en los Andes, ya que atiende a la mejora de las iglesias en los sitios más alejados de la ciudad y pueblos pequeños como Tignamar, Lupica y Tocoroma.

Finalmente, la permanencia de prácticas "paganas" en los Altos de Arica constituye un importante elemento de análisis. Sabemos que la evangelización 
de las poblaciones andinas no fue una empresa fácil. Después de la caída del Imperio Inca reaparecen prácticas religiosas locales (Marzal 1983). Los doctrineros de los Andes Centrales fueron los primeros en denunciar la permanencia de estos "cultos ancestrales" entre los indígenas. Tal denuncia hizo que las autoridades eclesiásticas implementaran una serie de medidas y campañas destinadas a extirpar prácticas religiosas tradicionales andinas identificadas como "idolatrías" durante el siglo XVII (Duviols 1971; Griffiths 1996; Mills 1997).

En el caso de los Altos de Arica, tal parece que las idolatrías constituyeron una constante que no fueron denunciadas con la misma frecuencia que en los Andes Centrales. Con toda seguridad esta es la razón por la cual la quema del pueblo de Isquiliza es uno de los episodios más citados dentro del relato de Vázquez de Espinosa ${ }^{17}$. Las motivaciones que lo llevaron a tomar esta decisión se basan en que la mayoría de sus habitantes eran, en su opinión, claramente idólatras. Los sermones aprobados por el Tercer Concilio Limense establecieron una línea divisoria con el pasado andino y drásticamente vincularon la religión indígena con el Demonio. Huaqas y ancestros prehispánicos fueron a partir de entonces vistos como herramientas que usaba Satanás para comunicarse con los vivos y condenar sus almas ${ }^{18}$. El texto específicamente establece que todos los que adoren huaqas y ancestros inexorablemente irán al infierno ${ }^{19}$.

¿Cómo se explica la persistencia de idolatría indígena en los Altos de Arica? La conversión de los indígenas no debe entenderse como un proceso unilineal, por el contrario, los nativos constantemente fluctúan entre la conversión y el paganismo, dependiendo de las circunstancias económicas o demográficas a las cuales se veían sometidos. En momentos de estrés, por ejemplo, los andinos retornan a sus prácticas religiosas ancestrales (Varón 1990:331-405). A esta acción se le ha denominado "cultos de crisis" (Curatola 1976).

Siguiendo este razonamiento, en el caso del Corregimiento de Arica es posible identificar una serie de causas que pudieron provocar la persistencia y revitalización de religiones ancestrales indígenas. En primer lugar, la explotación de la mano de obra indígena a causa del transporte del azogue de Arica a Potosí seguramente constituyó una fuente de estrés para los nativos. Referencias acerca de cómo eran sometidos a realizar esta tarea y los numerosos abusos cometidos por los españoles son abundantes. De hecho, el trayecto era conocido por los indios como "el camino de la muerte" (Álvarez 1998 [1588]: 640; Cavagnaro 1994:17; Galdames et al. 1981:63). En 1637 el entonces Obispo de Arequipa y futuro máximo exponente de las campañas de extirpación de idolatrías en los Andes Centrales, Pedro de Villagómez, visitó el Corregimiento de Arica y denunció los abusos cometidos por el Corregidor, quien enviaba a los indios a trabajar en distintos trajines con los españoles por el ínfimo valor de diez pesos por viaje. De esta manera, advierte Villagómez, los indios han ido muriendo y enfermando gravemente al punto de existir una alarmante disminución de indios varones en la zona (Hidalgo y Díaz 1985:81-82).

Otro elemento que con seguridad añadía estrés a la ya difícil vida cotidiana de los indios eran los desastres naturales. Sabemos que los terremotos, maremotos y erupciones volcánicas han sido constantes en el sur peruano. Tales eventos en tiempos coloniales provocaron no sólo el temor de la población, sino que además el surgimiento de manifestaciones de fe ancestral, recurso espiritual usado a fin de contrarrestar los nefastos acontecimientos. Para el caso de la zona que nos ocupa, una serie de antecedentes históricos indican que varios desastres naturales ocurrieron entre fines del siglo XVI e inicios del XVII.

En 1588 los dominicos informaron de inundaciones y terremotos que habían causado daños irreparables en Arequipa, al punto de haber sido forzados a detener sus actividades evangelizadoras entre los indios ${ }^{20}$. Para 1600, Fray Reginaldo de Lizárraga ofrece algunos antecedentes en su visita a los Altos de Arica y declara que sólo habitan seis indígenas en la ciudad de Arica por el temor que tienen a los frecuentes temblores "en los que hasta el agua tiembla" (Lizárraga 1946 [1603-1609]: 96). La erupción del Huayna Putina, en 1600, seguramente propagó el miedo entre la población, debido a que las cenizas llegaron hasta la ciudad de Arica, provocando una catástrofe que inmortalizó Guaman Poma de Ayala (Figura 2) ${ }^{21}$. Existen, además, referencias acerca de un temblor y maremoto ocurridos en 1604 (Dagnino 190:15). En 1608, la Audiencia de Lima compiló un informe General del Reino, donde indica el tipo de ayuda brindada a las ciudades de Arequipa y Arica para que se sobrepusieran a un terremoto e inundación sucedidos recientemente ${ }^{22}$. La zona fue asolada nuevamente por otra catástrofe poco tiempo después. 


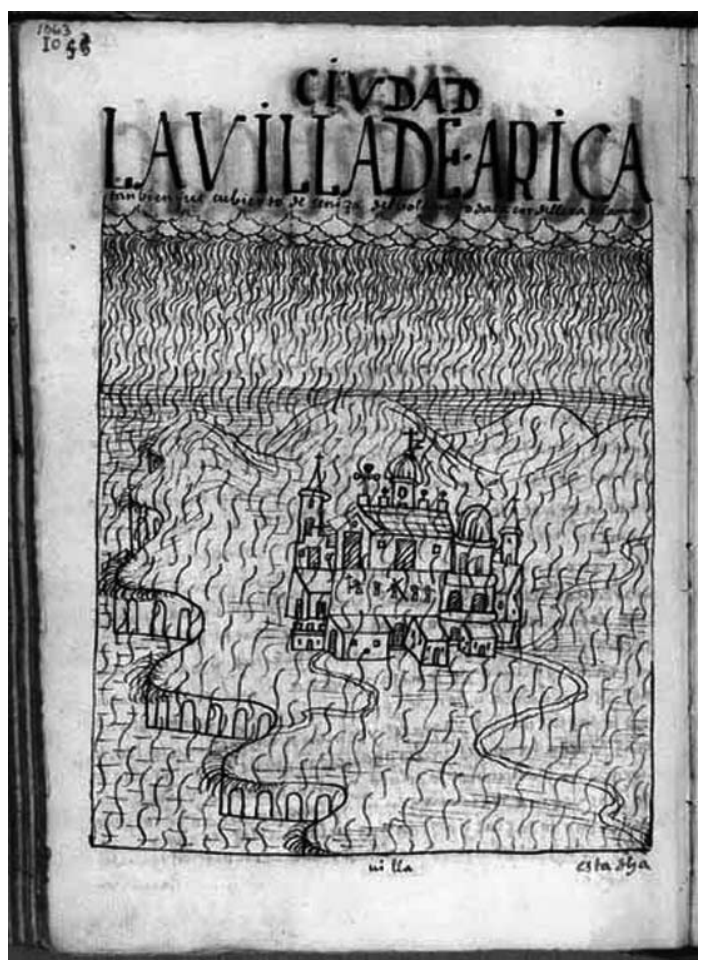

Figura 2. "LA VILLA DE ARICA tanbién fue cubierto de seniza del bolcán toda la cordellera de la mar. / uilla / CIVDAD" (Guaman Poma de Ayala 1615/1616: 1055 [1063]) www.kb.dk

"The town of Arica also was covered by volcanic ashes, all the coastal hills" (Guaman Poma de Ayala 1615/1616: 1055 [1063]) $w w w . k b . d k$

Para 1618, Vázquez de Espinosa manifestó haber sido testigo "de vista" de un terremoto y posterior salida de mar (Vázquez de Espinosa 1948 [1636]: párrafo 1404, p. 472) ${ }^{23}$. Estos desastres naturales continuaron afectando la vida de los nativos de la sierra de Arica en el siglo XVII, en una combinación de erupciones volcánicas, pestes y bajas demográficas (Hidalgo y Durston 1998:515).

La recurrencia de tales eventos en el sur peruano sin duda tuvo efecto sobre la persistencia del "paganismo" nativo en la zona. Ante estas circunstancias de estrés y temor los nativos muy probablemente revitalizaron sus creencias ancestrales. Por ejemplo, testigos de la erupción del Huayna Putina en 1600 declaran haber visto cómo los indios acudían a la cima del volcán para "ofrendar al Diablo" (Marsilli 2002:131-140). Cabe hacer notar que fortalecer las propias creencias religiosas en la víspera de un desastre natural no era exclusividad de las comunidades andinas. La Iglesia Católica en similares situaciones realizaba sus propias manifestaciones de "fe", como, por ejemplo, procesiones y penitencias varias (Walker 2004:31-55).

Cabe poca duda que la explotación de la mano de obra, la disminución de la población y las constantes amenazas de la naturaleza incentivaron a los indígenas de los Altos de Arica a mantener sus prácticas religiosas ancestrales. Es seguro que tal detalle no pudo escapar a los ojos de un viajero acucioso como Vázquez de Espinosa, un hombre por naturaleza ambicioso, un fraile ávido por cumplir con la palabra establecida en los Concilios Limenses $\mathrm{y}$, por sobre todo, un cortesano ansioso de ganar el favor de las más altas esferas de poder político dentro del imperio español.

\section{Conclusiones}

El "Compendio" de Vázquez de Espinosa debe ser entendido como una explicación post-factum de un viaje de largo y poco definido itinerario que el autor realizó por los dominios españoles del Nuevo Mundo. Los motivos iniciales del periplo no son conocidos. En cambio, la agenda ulterior del autor se puede suponer con facilidad. Vázquez de Espinosa elaboró su texto a su regreso a España, cuando ya era parte del selecto círculo de poder político de la corte imperial. Se trata, entonces, en realidad de una relación de méritos y servicios que debía servir a consolidar la posición del carmelita dentro de la red de poder del Conde-Duque de Olivares. La voz de Vázquez de Espinosa no es inocente ni desinteresada (se puede argüir que ningún autor en realidad lo es), sino que su prosa es la visión oficial-idealizante de la administración imperial. Denuncia lo que a ojos del sistema debe ser corregido e intenta obtener buenos beneficios personales de sus referidas acciones e ideas y en este contexto deben ser entendidas sus observaciones sobre la "idolatría" indígena. Atento a las fluctuaciones de la administración imperial acepta, por una parte, la posibilidad de convertir a los indios vía la persuasión y, por otra, se inclina ante una postura más violenta, donde vestigios de religiones prehispánicas no deben ni pueden ser tolerados. Esta ambivalencia entre discurso y acción por parte del carmelita pone en evidencia la "liminalidad" del autor, producto de una etapa de transición de la política de conversión indígena a nivel imperial.

No obstante lo anterior, Vázquez de Espinosa observó un real estado de abandono en la labor evangelizadora de los indios, por lo que la quema 
del pueblo de Isquiliza, real o ficticia, indica las deficientes condiciones de la vida religiosa de los indios o, al menos, lo suficientemente inferiores a las expectativas imperiales como para justificar (o hacer creíble) tal drástica decisión.

Como en todo ejercicio de lectura, es necesario en el caso del "Compendio" tener en cuenta un delicado balance entre la audiencia a quien el texto estaba destinado, la naturaleza personal del autor y los estándares de la prosa escogida, en cuanto ésta constituye el instrumento de la agenda de Vázquez de Espinosa. La tendencia literaria en la cual el "Compendio" se inserta es la "hibridización" de la narrativa colonial. La elección de tal estilo narrativo no es casual. La simultaneidad de discursos (geográficos, políticos, moralizantes, teológicos) sirve eficientemente a sus múltiples ambiciones personales: geógrafo, etnógrafo, misionero, teólogo. ¿Cómo compatibilizar estas múltiples lecturas con la realidad histórica?, probablemente se preguntará el lector. La tarea no es fácil para los especialistas, pero se puede añadir que, como en todo escrutinio del pasado usando fuentes escritas, la verdad se halla en un punto intermedio entre lo referido y lo posible.

Agradecimientos: Este artículo se completó durante el desarrollo de una beca postdoctoral de FONDECYT, 2006-2007 (№ 3060120), otorgada a la primera autora y realizada como profesor visitante en el Centro de Investigaciones del Hombre en el Desierto (CIHDE) de la Universidad de Tarapacá, Arica-Chile, que actuó como institución ejecutora. Se agradece también el apoyo del Departamento de Antropología de dicha Universidad. Las autoras también reconocen la paciente labor de los anónimos evaluadores de Chungara, quienes ofrecieron sugerencias y acertados consejos a versiones anteriores de este artículo. La segunda autora cuenta con beca CONICYT de postgrado.

\section{Referencias Citadas}

\section{Siglas}

AAA: Archivo Arzobispal de Arequipa.

AGI: Archivo General de Indias (Sevilla, España).

AAA, Arica-Codpa, 1560-1891. Visita de la Doctrina de Codpa y Azapa y sus anejos, 1650.

AGI, Lima 36. Autos de la División de los Obispados de Guamanga y Arequipa separados del Cuzco. Por Nuestro Sanctisimo Padre Papa Paulo V, 1614.

AGI, Lima 317, Carta de Fray Pedro de la Serna, Procurador General de la Provincia de San Juan Bautista del Perú de los Predicadores al Virrey, 1588.

AGI, Lima 95, Estado General del Reyno hecho por la Audiencia de Lima, 1608.

\section{Fuentes impresas}

Álvarez, B.

1998 [1588] De las Costumbres y Conversión de los Indios del Perú. Memorial a Felipe II. Ediciones Polifemo, Madrid.

Lizárraga, Fray R.

1946 [1603-1609] Descripción de las Indias, editado por Carlos A. Romero y Francisco A. Loayza, Asociación Editora Los pequeños Grandes Libros de Historia Americano, Serie I, Tomo XII, Lima.

Vázquez de Espinosa, A.

1948 [1636] Compendio y descripción de las Indias Occidentales, editado por Ch. Upson Clark. Smithsonian Institution, Washington.

\section{Fuentes publicadas}

Acosta, A.

1987 Estudio biográfico sobre Francisco de Ávila. En Ritos y Tradiciones de Huarochiri. Manuscrito Quechua de Comienzos del siglo XVII, editado por G. Taylor, pp. 552616. IEP-IFEA, Lima.
Bouysse-Cassagne, T. y P. Bouysse

1984 Volcan Indien, volcan chrétien. A propos de l'éruption du Huaynaputina en l'an 1600 (Pérou méridional). Journal de la Société des Américanistes Tomo LXX.

Cavagnaro, L.

1994 Materiales para la historia de Tacna, Tomo III: Dominación Hispánica s. XVII. Editorial de la Universidad Privada de Tacna, Tacna-Perú.

Cook, N.

1982 Population data for Indian Peru: Sixteenth and seventeenth centuries. Hispanic American Historical Review 62:73-120.

Crom, W.

1988 La interpretación de fuentes históricas: ejemplos del Valle de Azapa-Arica Chile. Diálogo Andino 7/8: 45-56.

Cúneo-Vidal, R.

1977 Historia de la fundación de la ciudad de San Marcos de Arica. En: Rómulo Cúneo-Vidal, Obras Completas, Tomo 5, Volumen IX, editado por I. Prado, pp. 7-213, Gráfica Morsom, Lima.

Curatola, M.

1976 Mito y milenarismo en los Andes: del Taqui Onqoy e Inkarri. Allpanchis 9:65-92.

Dagnino, V.

1907 El Corregimiento de Arica. Imprenta La Época, Arica.

Durston, A. y J. Hidalgo

2004 La presencia andina en los valles de Arica, siglos XVI-XVIII: casos de regeneración colonial de estructuras archipielágicas. En Historia Andina en Chile, editado por J. Hidalgo, pp. 479-506. Editorial Universitaria, Santiago. Duviols, P.

1971 La Lutte Contre les Religions Autochtones dans le Pérou Colonial L'Extirpation de L'Idolatrie entre 1532 et 1660. IFEA, Lima. 
Elliott, J.

1990 Imperial Spain. 1469-1716. Penguin Books, New York.

Galdames, L., W. Ríos, Dauelsberg, Chacón y L. Álvarez 1981 Historia de Arica. Ilustre Municipalidad de Arica, Editorial Renascimiento, Arica.

Griffiths, N.

1996 The Cross and the Serpent. Repression and Resurgence in Colonial Peru. University of Oklahoma Press, Lincoln.

Guamán Poma de Ayala, F.

1980 [1615] El Primer Nueva Corónica y Buen Gobierno, editado por J. Murra y R. Adorno. Editorial Siglo XXI-IEP, México.

Hidalgo, J.

1982 Etnohistoria e interdisciplinariedad en Chile desde sus orígenes hasta 1980. En Historia Andina en Chile, editado por J. Hidalgo, pp. 655-683. Editorial Universitaria, Santiago.

Hidalgo, J. y V. Díaz

1985 Cartas del Obispo de Arequipa sobre los indios del Corregimiento de Arica: 1620-1638. Chungara 15:77-97.

Hidalgo, J. y A. Durston

1998 Reconstitución étnica colonial en la sierra de Arica: el Cacicazgo de Codpa, 1650-1780. En Historia Andina en Chile, editado por J. Hidalgo, pp. 507-533. Editorial Universitaria, Santiago.

Hardoy, J. y C. Aranovich

1967 Cuadro comparativo de los centros de colonización española existentes en 1580 y 1630. Desarrollo Económico 7(27):249-260, Buenos Aires.

Lehman, S.L.

2008 La ética colonial tras las interpolaciones en la Luz y Guía del Cielo de Antonio Vázquez de Espinosa. Revista de Crítica Literaria Latinoamericana 34(68):81-96, LimaHanover.

López-Cordón de Cortezo, M.V.

2003 Entre damas anda el juego: las camareras mayores de Palacio en la edad moderna. Cuadernos de Historia Moderna, Anejo II, pp. 123-152.

MacCormack, S.

1986 El corazón tiene sus propias razones: categorías del cristianismo misionero en el Perú Colonial temprano. Historia Boliviana 1-2:17-41.

Málaga Núñez Zeballos, A.

$2002 \mathrm{El}$ enojo de los dioses: terremotos y erupciones en Arequipa del siglo XVI. En El Hombre y los Andes. Homenaje a Franklin Pease G.Y., editado por J. Flores Espinoza y R. Varón G., Tomo II, pp. 905-914. Pontificia Universidad Católica del Perú, Lima.

Marsilli, M.

2002 God and Evil in the Gardens of the Andean South: Mid-Colonial Rural Religion in the Diocese of Arequipa. Tesis Doctoral, Emory University, Atlanta.

2004 Missing idolatry: Interactions between parish priests and indians in the Colonial Diocese of Arequipa. Colonial Latin American Historical Review 13:399-421.

2010 Volcanes locuaces e inextinguible fuego interior. La erupción del Huaynaputina en 1600 en la narrativa jesuítica.
En Escritura, Imaginación Política y la Compañía de Jesús, editado por T. Hampe-Martínez y A. Coello de la Rosa. Ediciones Bellaterra, Barcelona, en prensa.

Marzal, M.

1983 La Transformación Religiosa Peruana. Pontificia Universidad Católica del Perú, Lima.

Mills, K.

1997 Idolatry and its Enemies: Colonial Andean Religion and Extirpation, 1640-1750. Princeton University Press, Princeton.

Murra, J.

1975 Formaciones Económicas y Políticas del Mundo Andino. Instituto Estudios Peruanos, Lima.

Negredo del Cerro, F.

2002 La Hacienda y la conciencia. Las propuestas del confesor del Conde Duque para el saneamiento de las finanzas reales (1625). Cuadernos de Historia Moderna 27:171-196.

Pärssinen, M.

1992 Tawantinsuyu: The Inca State and Its Political Organization. SHS Suomen Historiallinen Seura, Helsinki.

Pease, F.

1995 Las Crónicas y los Andes. Pontificia Universidad Católica del Perú, Instituto Riva-Agüero- Fondo de Cultura Económica, Lima.

Sánchez Albornoz, N.

1978 Indios y Tributos en el Alto Perú. IEP, Lima.

Santoro, C. e I. Muñoz

1981 Patrón habitacional incaico en el área de Pampa Alto Ramírez. Chungara 7:144-171.

Trelles, E.

1982 Lucas Martínez Vegazo: Funcionamiento de una Encomienda Peruana Inicial. Pontificia Universidad Católica del Perú, Lima.

Upson Clark, Ch.

1948 Prólogo. En Compendio y Descripción de las Indias Occidentales, editado por A. Vázquez de Espinosa [1636], pp. III-XII. Smithsonian Institution, Washington.

Vargas Ugarte, R.

1951-54 Concilios Limenses (1551-1772), Tomos I y II, Tipografía Peruana, Lima.

Varón, R.

1990 El Taki Onqoy: las raíces andinas de un fenómeno colonial. En El Retorno de las Huacas. Estudios y Documentos del Siglo XVI, editado por L. Millones, pp. 331-405. Instituto de Estudios Peruanos, Sociedad Peruana de Psicoanálisis, Lima.

Villalobos, $\mathrm{S}$.

1986 La Obra de Vázquez de Espinosa. En Descripción del Reino de Chile, pp. 7-31. Instituto Blas Cañas, Santiago.

Walker, Ch.

2004 Desde el terremoto a las bolas de fuego: premoniciones conventuales sobre la destrucción de Lima en el siglo XVIII. Relaciones 97:31-55.

Wormald, A.

1972 Historias Olvidadas del Norte Grande. Universidad del Norte, Arica. 
Notas

1 El Corregimiento de Arica dependía del Obispado del Cusco desde 1538. En 1614 el Virrey Márquez de Montesclaros oficializó la creación del Obispado de Arequipa, del que dependerá el Corregimiento. Archivo General de Indias (en adelante AGI), Lima 36. Autos de la División de los Obispados de Guamanga y Arequipa separados del Cuzco. Por Nuestro Sanctisimo Padre Papa Paulo V.

2 La ubicación de los lugares mencionados en el viaje del carmelita se encuentra en la Figura 1.

3 Charles Upson Clark se encontraba en comisión por la Smithsonian Institution buscando documentos inéditos sobre las viejas culturas americanas. El interés que este manuscrito "anónimo" suscitó en el investigador, alcanzó su éxito con la publicación del texto en inglés en 1942 y en 1948 en español (Upson Clark 1948:IV).

4 Estos antecedentes fueron encontrados por Charles Upson Clark en la Enciclopedia universal Espasa (Upson Clark 1948:III).

5 Entre ellos: Viaje y Navegación del año 1622 que hizo la Flota de Nueva España y Honduras (Málaga, 1624); Sumario de Indulgencias (Málaga, 1627); Circunstancias para los Tratos y Contratos de las Indias del Perú y Nueva España (Málaga 1624).

6 En el Compendio se evidencian las estrechas relaciones que Vázquez de Espinosa tuvo con el Gobierno Español y la Iglesia. Entrega recomendaciones para mejorar la administración de las Indias, tales como sugerir al Consejo de Indias nombramientos de Obispos para Florida, Huánuco y Arica, o instrucciones para mejorar las defensas de las ciudades de Arica y Santo Domingo. Destaca también su interés por la economía de las provincias, ofreciendo minuciosas observaciones de las actividades que desarrollan sus habitantes. En lo religioso, el carmelita organiza procesiones, celebra festividades religiosas, inspecciona el trabajo de los sacerdotes y da cuenta del estado de la evangelización de la población indígena.

7 El poder del Conde-Duque se demuestra en el hecho de que su esposa, la Condesa de Olivares, fue camarera mayor de la Reina, a pesar de que dicho cargo era destinado exclusivamente para mujeres viudas. Dentro de las funciones de la camarera estaban la asistencia personal de la reina y algunas atribuciones de gobierno. Este cargo suponía contacto físico y directo con el soberano (López-Cordón de Cortezo 2003). Para un análisis de la España del siglo XVII, véase Eliott (1990:323-349).

8 Esto queda demostrado en el papel que cumplió el padre Salazar, confesor del Conde-Duque de Olivares, en las decisiones tomadas para cambiar el sistema de Hacienda del reino. La condición de clérigo beneficiaba a los confesores para ocupar cargos de confianza, ya que estarían ajenos a las tentaciones terrenales del poder y el dinero (Negredo del Cerro 2002:174).

$9 \quad$ No existen referencias de las motivaciones del autor para elaborar la obra (Villalobos 1986). Probablemente el cargo que el carmelita ocupó a su regreso debió en parte ser mérito de sus minuciosas observaciones, por ejemplo, los numerosos datos geográficos ofrecidos en el Compendio. Tal vez en esta posición Vázquez de Espinosa logró obtener acceso a documentos oficiales que ayudaron a precisar algunos datos presentes en la obra.

10 Sobre el rol que la comunidad científica europea jugó en la recopilación de información científica procedente del Nuevo Mundo en la España del siglo XVII, véase María N. Marsilli "Volcanes Locuaces e Inextinguible fuego interior. La erupción del Huayna Putina en 1600 en la narrativa jesuítica" de próxima publicación en: Hampe, T. y Alexandre Coello de la Rosa, Escritura, Imaginación Política y la Compañía de Jesús, Ediciones Bellaterra, Barcelona-España.

11 El texto habría sido escrito en 1628 y revisado e impreso en 1629. Paul Rivet señala que Vázquez de Espinosa recibió permiso para imprimir su libro el 12 de noviembre de 1629 (Upson Clark 1948:IX).

12 Para una visión comparativa de la importancia de Arica con otras ciudades visitadas por Vázquez de Espinosa durante su viaje, véase Hardoy, J. y Carmen Aranovich, "Cuadro comparativo de los centros de colonización española existente en 1580 y 1630" en Desarrollo Económico, Vol. 7, № 27, (octubre-diciembre 1967), pp. 249-260.

13 Es importante señalar algunos antecedentes sobre los pueblos visitados por el carmelita. Para Wormald (1972) el pueblo reconocido como Tocroroma correspondería a Pachama, en cambio Hidalgo (1977) señala que Tocoroma es Belén. Hemos aceptado para la elaboración del mapa de los lugares visitados por el carmelita esta última relación. En cuanto al lugar nombrado como Lagnama, hemos seguido a Wormald, quien señaló que correspondía a Ticnamar Viejo.

14 Era una práctica usual de los cronistas del siglo XVI y XVII copiarse entre ellos algunos datos. En 1975 Murra llamó la atención sobre la necesidad del rastreo sistemático de algunas fuentes primarias para descubrir "quién copió a quién". Pärssinen (1992) señala que esta práctica usada por los cronistas dificulta el trabajo de los historiadores.

15 Ya hacia 1590 José de Acosta releyendo escritos misioneros precedentes establecía que la religión tradicional andina estaba basada pura y simplemente en errores humanos. "La "sublime verdad del Catolicismo", escribía, sólo será alcanzada por los indios si estos antes son liberados de sus demonios ancestrales (MacCormack 1986:208). Hacia 1609, Francisco de Ávila decidió denunciar públicamente la idolatría de los indios de su parroquia de San Damián de Huarochiri y quemar sus ídolos en la plaza de Lima (Mills 1997:28-29). El gesto tuvo una profunda repercusión en la Archidiócesis limeña y marcó el inicio de las campañas de extirpación de idolatrías. Tales iniciativas alcanzarán su clímax hacia 1630, durante la administración de Pedro de Villagómez, quien antes había servido como Obispo de Arequipa (Marsilli 2002:40-44).

16 Para un análisis detallado de las "oposiciones" (concursos públicos para obtener el nombramiento en doctrinas de indios) y las dinámicas de interacción entre líderes indígenas y curas doctrineros en la construcción de los memoriales de méritos y servicios de los sacerdotes, véase Marsilli, $\mathrm{M}$. 2004:410-412.

17 La ubicación del pueblo de Isquiliza es uno de los grandes cuestionamientos y puntos de interés del Compendio, tanto para arqueólogos como para antropólogos e historiadores. El hallazgo de restos de una aldea quemada en el sitio AZ-15 ha 
permitido relacionarlo con el poblado de Isquiliza (Santoro y Muñoz 1981:163).

18 Tercero Catecismo y Exposición de la Doctrina Christiana, por Sermones para que los Curas y Otros Ministros Prediquen y Enseñen a los Indios y a las Demas Personas conforme a lo que en el Santo Concilio Provincial de Lima se proveyo, (Lima, 1585), en Estudios Bolivianos 9, Special Issue: El discurso de la Evangelización del Siglo XVI (La Paz: Universidad Mayor de San Andrés, 2001), 279-281.

19 Ibid., pp. 294-300.

20 AGI, Lima 317, Carta de Fray Pedro de la Serna, Procurador General de la Provincia de San Juan Bautista del Perú de los Predicadores al Virrey, 1588, folio único.
21 Sobre las diferencias en la percepción del cataclismo por parte de los españoles e indios, véase Bouysse-Cassagne y Bouysse (1984). Además de la erupción de 1600, Alejandro Málaga Ñúñez Zevallos (2002) ha descrito el primer sismo registrado por la población hispana de Arequipa, en 1582.

22 AGI, Lima 95, 1608, Estado General del Reyno hecho por la Audiencia de Lima, 4 fols.

23 Es importante realizar un alcance en cuanto a la datación del evento, puesto que los datos recopilados por historiadores y geógrafos apuntan a que la catástrofe ocurrió en 1615, específicamente el 16 de septiembre de ese año (Cavagnaro 1994; Crom 1988; Cúneo-Vidal 1977; Dagnino 1907). 